\title{
Evolution of Ultrafine-grained Ferrite in Hot Successive Deformation*
}

\author{
By Yoshikazu MATSUMURA ${ }^{* *}$ and Hiroshi YADA A** $^{* *}$
}

\begin{abstract}
Synopsis
Large deformation for a common $\mathrm{C}-\mathrm{Mn}$ steel at the temperatures around $\mathrm{Ar}_{3}$ results in an ultrafine-grained ferrite structure. This is due to dynamic transformation and recrystallization of ferrite during deformation. To apply the new finding to an actual plant rolling, multi-pass deformations which substitute for a single pass heavy deformation have been studied.

It was realized that when the interpass time during successive deformations is shorter than $2 s$, the effect of accumulative strain can make ferrite grains fine.

A trial of strip rolling in plant provided a mean ferrite grain size of ASTM No. 13.5 .
\end{abstract}

Key words: phase transformation; hot deformation; recrystallization; strain; carbon steel; ferrite; fine grain.

\section{Introduction}

As fine grained steels show many favorable mechanical properties such as strength, ductility, impact property, etc., grain refinement has been an important item among research studies. The conventional methods of grain refinement for as hot-rolled ordinary steels can be summarized as follows: i) recrystallization of austenite (ex., low temperature and large reduction rolling), ii) the increase of ferrite nuclei by the increase of the degree of the supersaturation for transformation (ex., rapid cooling after rolling), iii) the increase of ferrite nucleation sites in nonrecrystallized austenite by introducing many defects by rolling. The third way is termed as 'controlled rolling'. Controlled rolling of $\mathrm{Nb}$ microalloyed steels is thought to be the most effective way to produce fine grained steel plates in rolling plants. The minimum ferrite grain size of commercially rolled steels is around $3 \sim 5 \mu \mathrm{m}$ (ASTM Nos. 12 13). ${ }^{1,2}$ )

Recently, the authors have found a new grain refinement method which comprises dynamic transformation during deformation (so called deformation induced transformation) and the dynamic recrystallization of ferrite. ${ }^{3,4)}$ It is able to obtain ferrite grains finer than $3 \mu \mathrm{m}$ in common carbon steels. Both ferrite grain size and amount of ferrite formed by the dynamic transformation strongly depend on the strain given to a steel. According to a single pass deformation experiment, the reduction of $80 \%$ is necessary to obtain ultrafine ferrite with a fraction exceeding a half in the microstructure. ${ }^{5,6)}$ As such a large reduction is not applicable in plant rolling, it is important to prove if cumulative deformations can substitute for the single heavy deformation.

This report deals with the structure change of a steel during multi-pass deformations to produce ultrafine-grained $(<3 \mu \mathrm{m})$ ferrite.

\section{Experimentals}

Experiments were carried out in the three ways. i) 2-stage deformation test by a compression type hot successive deformation simulator to examine the effects of the interpass time and subsequent deformation on the microstructure of steel, ii) 2-pass rolling test to confirm the above results by rolling, and iii) 6 -stage compression test by the simulator for cumulative hot rolling in a plant.

The details of the simulator were described elsewhere. ${ }^{7)}$

\section{Two-stage Deformation Test by a Hot Deformation Simulator}

The steels with the compositions shown in Table 1 were made by a $300 \mathrm{~kg}$ vacuum furnace and cast into $150 \sim 300 \mathrm{~kg}$ ingots. Steel A was hot rolled to $12 \mathrm{~mm}$ thick plates and machined into specimens of a size of $10 \mathrm{~mm} \times 15 \mathrm{~mm} \times 180 \mathrm{~mm}$ for the simulator.

Figure 1 shows the procedure of 2-stage test. A specimen was heated to $1273 \mathrm{~K}$, held for $3 \mathrm{~min}$ and

Table 1. Compositions of steels investigated. (wt \%)

\begin{tabular}{cccccccc}
\hline Steel & C & Si & Mn & P & S & Al & N \\
\hline A & 0.11 & 0.02 & 1.00 & 0.024 & 0.004 & 0.017 & 0.0017 \\
B & 0.11 & 0.02 & 0.97 & 0.003 & 0.002 & 0.024 & 0.0019 \\
C & 0.13 & 0.32 & 1.07 & 0.014 & 0.002 & 0.032 & 0.0050 \\
\hline
\end{tabular}

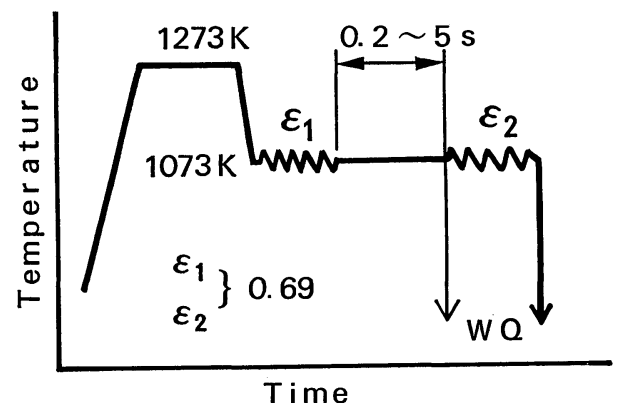

Fig. 1. Schematic of 2-pass deformation test by a simulator.

\footnotetext{
* Based on the paper presented to the 108th ISIJ Meeting, October 1984, S1487, at Hiroshima University in Hiroshima. Manuscript received on September 8, 1986; accepted in the final form on March 13, 1987. (C) 1987 ISIJ

** Nagoya R \& D Laboratory, Nippon Steel Corporation, Tokai-cho, Tokai 476.

*** Sheet \& Coil Research Laboratory, R \& D Laboratories-II (stationed at Higashida), Nippon Steel Corporation, Edamitsu, Yahatahigashi-ku, Kitakyushu 805.
} 
air cooled to the deformation temperature of $1073 \mathrm{~K}$. Deformations were given in 2 stages with intervals between 0.2 and $5 \mathrm{~s}$. The strain of each deformation was 0.69 . The specimen was water quenched within $0.056 \mathrm{~s}$ after the 2nd deformation. Evolution of microstructures was followed by quenching the specimens finished by the 1st stage deformation after a lapse of predetermined times.

Microscopic observations were made on a specific area of the lateral section of a specimen where the strain is equal to the nominal strain; $2 \mathrm{~mm}$ apart from the center of the deformed part. To examine the effect of an extremely large strain additional observations were also made on the midsection where strain was concentrated.

\section{Two-pass Rolling Test}

The steel used for this experiment was steel B in Table 1. The specimen with a size of $12 \mathrm{~mm} \times$ $30 \mathrm{~mm} \times 120 \mathrm{~mm}$ was prepared from a $12 \mathrm{~mm}$ thick plate. It was heated to $1273 \mathrm{~K}$, held for $30 \mathrm{~min}$ and air cooled to the rolling temperature of $1073 \mathrm{~K}$. The dimension of the rolling apparatus used is given in Table 2. The interpass time and the interval between the 2nd pass and water quenching were fixed at 5 and $2 \mathrm{~s}$, respectively.

\section{Simulated Six-stage Successive Deformation for Plant Rolling}

The steel used for this experiment was steel $\mathrm{G}$ in Table 1. The scheme of 6-stage deformation was chosen as in Table 3 in order to follow an actual successive rolling in a plant. A specimen was water quenched both before and after each pass as schematically shown in Fig. 2.

Table 2. Conditions of rolling test.

$\begin{array}{ll}\text { Roll diameter : } & 250 \mathrm{~mm} \\ \text { Rolling speed : } & 20 \mathrm{rpm} \\ \text { Rolling temperature : } & 1073 \mathrm{~K} \\ \text { Draft 1st pass : } & 10 \sim 4 \mathrm{~mm}(17 \sim 67 \%) \\ \quad \text { 2nd pass : } & 7 \sim 1.5 \mathrm{~mm}(13 \sim 33 \%) \\ \text { Interpass time : } & 5 \mathrm{~s} \\ \text { Water quenching : } & 2 \mathrm{~s} \text { after rolling }\end{array}$

Table 3. Schedule of 6-pass deformation test simulating continuous rolling in a plant.

\begin{tabular}{|c|c|c|c|c|}
\hline Pass & No. & Strain & $\begin{array}{c}\text { Strain rate } \\
\left(\mathrm{s}^{-1}\right)\end{array}$ & $\begin{array}{c}\text { Interpass time } \\
\text { (s) }\end{array}$ \\
\hline & 1 & 0.36 & 6.2 & \multirow[t]{2}{*}{5.1} \\
\hline & 2 & 0.36 & 10.7 & \\
\hline & 3 & 0.52 & 24.5 & 3.5 \\
\hline & 4 & 0.53 & 62.1 & 1.8 \\
\hline & 5 & 0.14 & 118.0 & 1.1 \\
\hline & 6 & 0.10 & 107.0 & 0.7 \\
\hline
\end{tabular}

\section{Results}

\section{Two-stage Deformation Test by Simulator}

Figure 3 shows the change in the ferrite grain size and the amount of the ferrite after the 1st and 2nd deformation as a function of holding time after the $1 \mathrm{st}$ deformation. Within $1 \mathrm{~s}$ after the $1 \mathrm{st}$ deformation, ferrite grains were kept very small and the amount of ferrite, $f_{\alpha}$, slightly decreased. By holding a specimen for longer than $2 \mathrm{~s}$, the very fine grains seemed to grow rapidly to a size larger than $3 \mu \mathrm{m}$ (ASTM No. 13). The ferrite fraction after $5 \mathrm{~s}$ was about 0.3 . The 2 nd deformation was effective both on grain refinement and the increase of ferrite fraction. Grains were refined by $30 \%$ (open marks to solid marks in Fig. 3) and the amount of ferrite $\left(f_{\alpha}\right)$ increased. The effect of grain refinement by the 2nd deformation seems to depend on the interpass time or the prior fine grain size. Although it is not clear which is more important mechanism for the grain refinement, the above results imply that if the

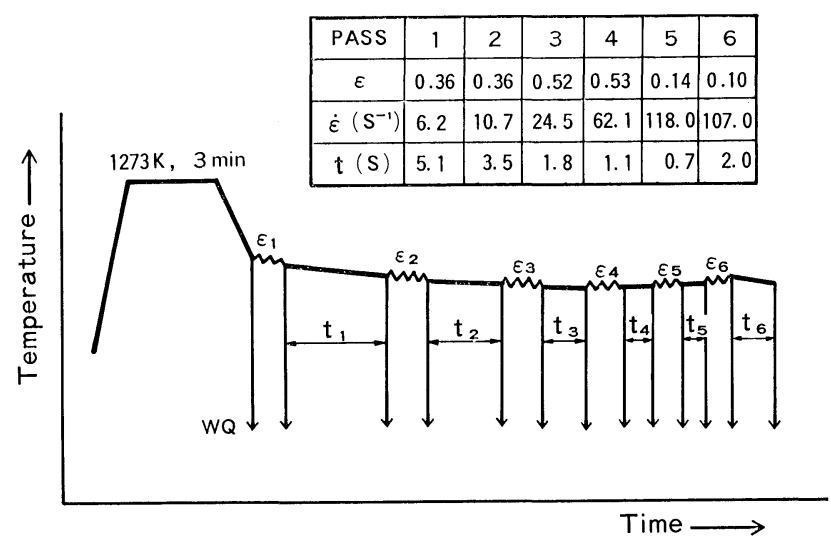

Fig. 2. Schematic of 6-pass deformation test by a simulator.

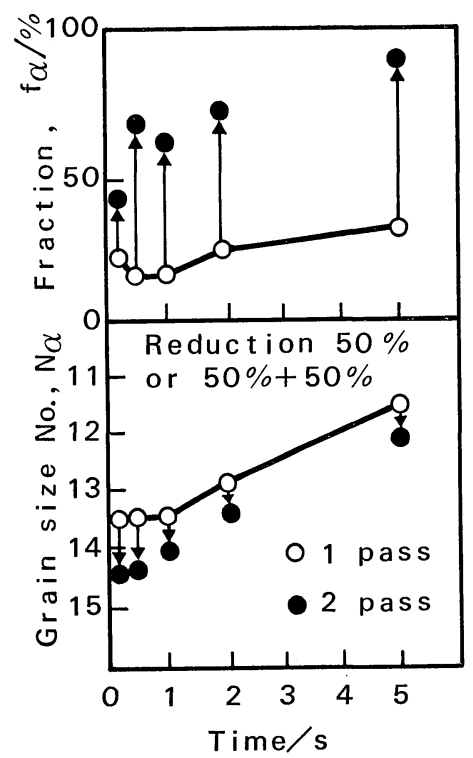

Steel: A (0.11G-1.0Mn)

Fig. 3. Effects of the interpass time and the 2nd deformation on ferrite structure. 
interpass time is shorter than $2 \mathrm{~s}$, there is a probability to obtain ultrafine-grained ferrite even by rolling in plant.

\section{Two-pass Rolling}

Figure 4 shows the effect of total strain of the 2pass rolling tests on the ferritic structure: $\varepsilon_{1}$ in the figure represents the strain of the 1st pass and the dotted lines represent the results of 1 -stage deformation tests by the simulator.

As the effect of strain accumulation was not strong because of the long interpass time of $5 \mathrm{~s}$, the grains after 2-pass rolling were coarser than those after 1stage deformation of the same total strain. However, it is clear that the increase of both reductions in the 1st and 2nd passes is effective to refine ferrite grain size. If the reduction in each pass is greater than $0.69(50 \%)$, fairly fine ferrite grains are obtainable even by 2-pass rolling as in 1-pass rolling of a large reduction.

Figure 5 shows the contours of equivalent grain size as a function of the strains of the 1st and 2nd passes, $\varepsilon_{1}$ and $\varepsilon_{2}$. The apparent effect of $\varepsilon_{1}$ on grain refinement is weaker than that of $\varepsilon_{2}$ because of the growth during interpass time. Therefore, it is important to increase the reduction in the final deformation from the practical point of view. However, when $\varepsilon_{1}$ is greater than 0.5 , the minimum strain of $\varepsilon_{2}$ to obtain ultrafine-grained ferrite is much decreased.

\section{Six-stage Plant Simulation}

Figure 6 shows the microstructures in a 6 -stage deformation test.

Even after the 1st stage, ferrite was formed along the prior austenite grain boundaries.

During pass intervals, ferrite grains tended to grow. The change in the grain size and the fraction of ferrite is shown in Fig. 7. In the first 3 stages, ferrite

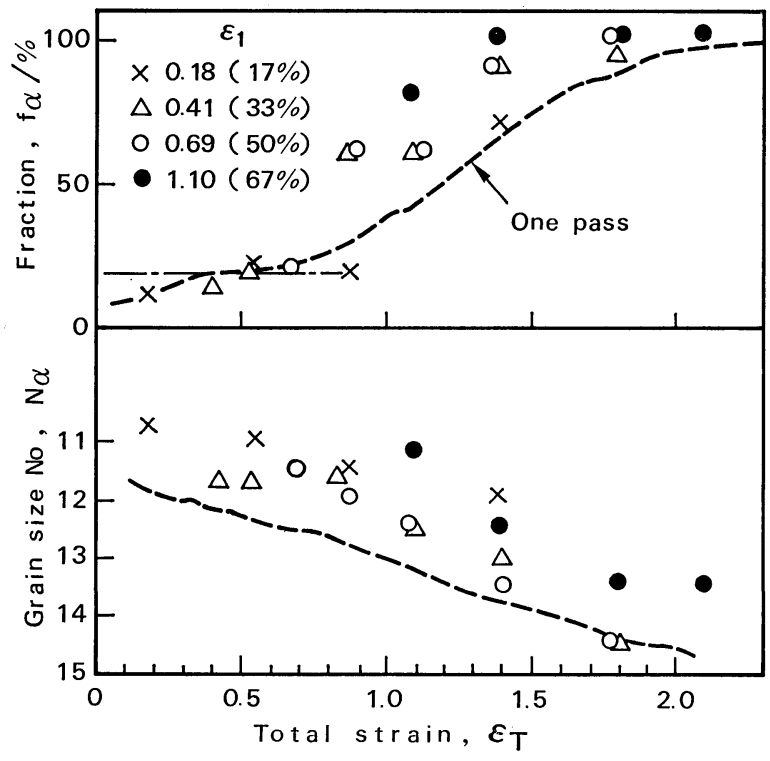

Steel: B $(0.11 \mathrm{C}-0.97 \mathrm{Mn})$

Fig. 4. Effect of the total strain of 2-pass rolling test on ferrite structure. grains were refined by each stage but grew during pass intervals, and their size remained between Nos. 12 and 13, while it abruptly decreased at the 4th stage because of the shorter interpass time than $2 \mathrm{~s}$.

The final structure comprised recrystallized ferrite which contains more dislocations than statically recrystallized ferrite and newly transformed ferrite.

At the completion of the last stage, a small amount of untransformed austenite remained. This means that even a short interval between the completion of deformation and the beginning of water cooling would result in considerable structure change. The ferrite grains would grow rapidly and the fraction would increase, since finer grains result in more rapid growth because of the higher driving force due to the small curvature of boundaries, while the number of dislocations might decrease to restore the deformation strain.

\section{Discussion}

It is of interest to consider the possibility of deformation induced transformation at higher temperature region of austenite phase. It is well known that the deformation of austenite at low temperature region accelerates ferrite transformation. ${ }^{8,9)}$ The transformation temperature of strained austenite is higher than that of unstrained austenite. This is clearly seen in Nb-microalloyed steels. When the deformation temperature is higher, however, the elevation of transformation temperature has hardly been observed because generated dislocations disappear by recrystallization. According to an energetic approach, ${ }^{10)}$ it may occur even at higher temperatures than $\mathrm{Ae}_{3}$. Figure 8 shows the results of a dilatmetric test of steel $B$ to examine the volume change subsequent to deformation at various temperatures. At the lower temperatures than $1073 \mathrm{~K}$, the volume of a specimen

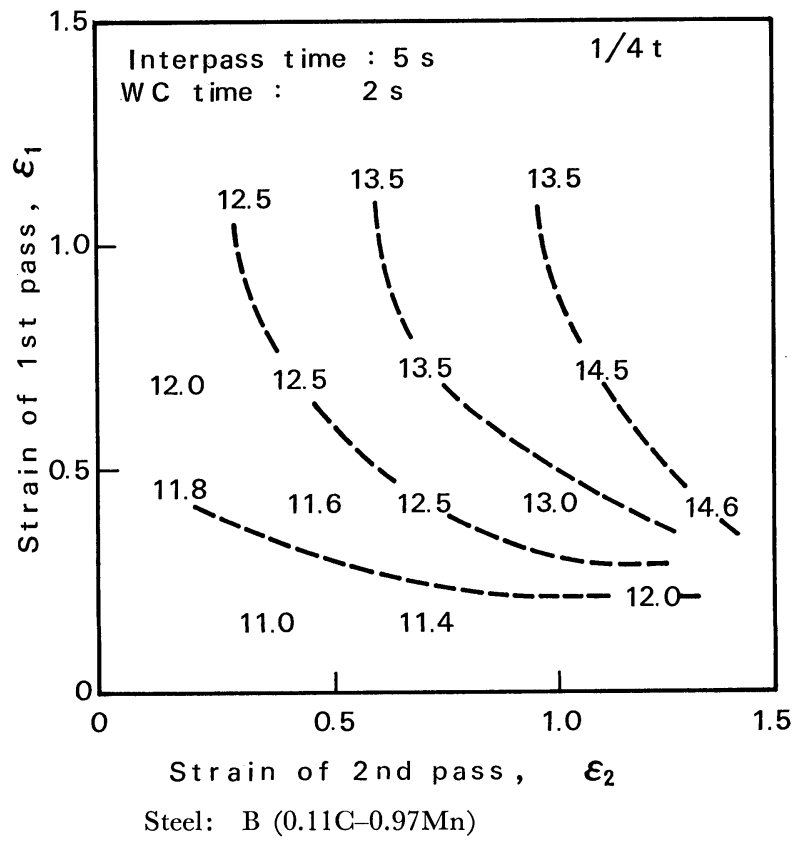

Fig. 5. Effects of the 1st and the 2nd deformations on grain size. 
gradually increased, showing the ferrite transformation. The volume decrease observed in the tests at temperatures of $1098 \sim 1123 \mathrm{~K}$ shows the decrease of ferrite. At high temperatures ferrite is thermo- dynamically unstable so that it reverts to austenite. This is new evidence showing that ferrite has transformed by deformation at temperatures higher than $\mathrm{Ae}_{3}$.

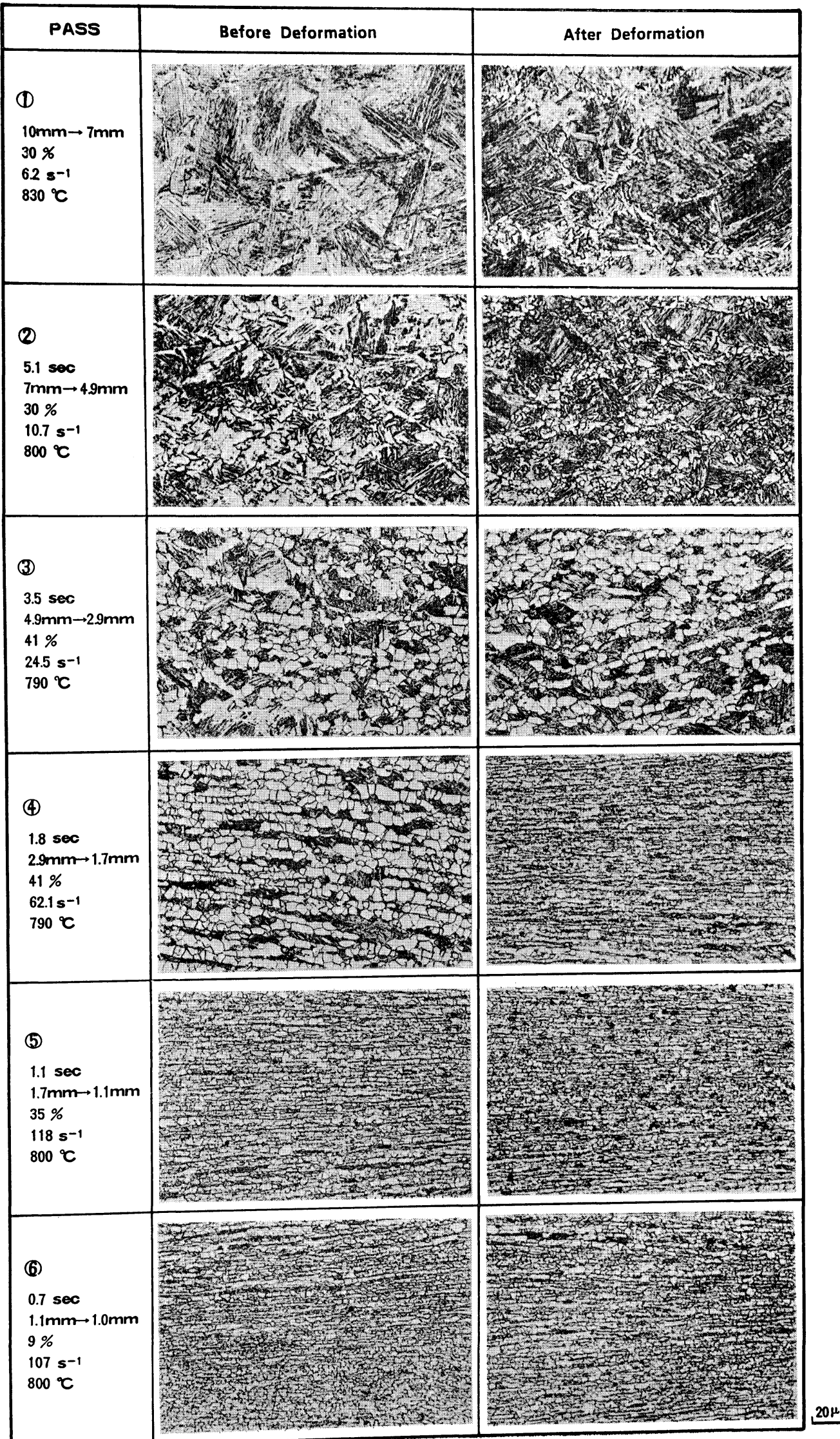




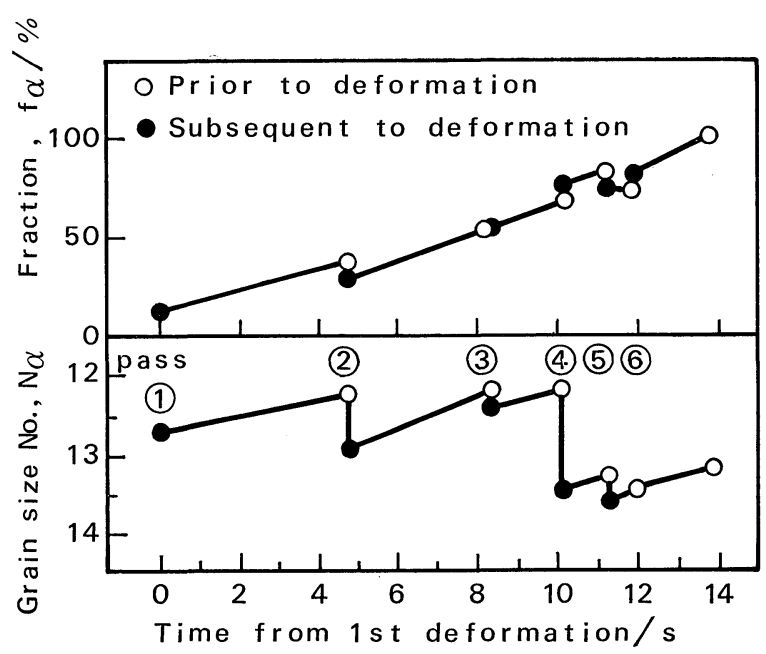

Steel: $\quad$ C $(0.13 \mathrm{C}-0.32 \mathrm{Si}-1.07 \mathrm{Mn})$

Fig. 7. Change in the grain size and the fraction of ferrite during 6-pass continuous deformations.

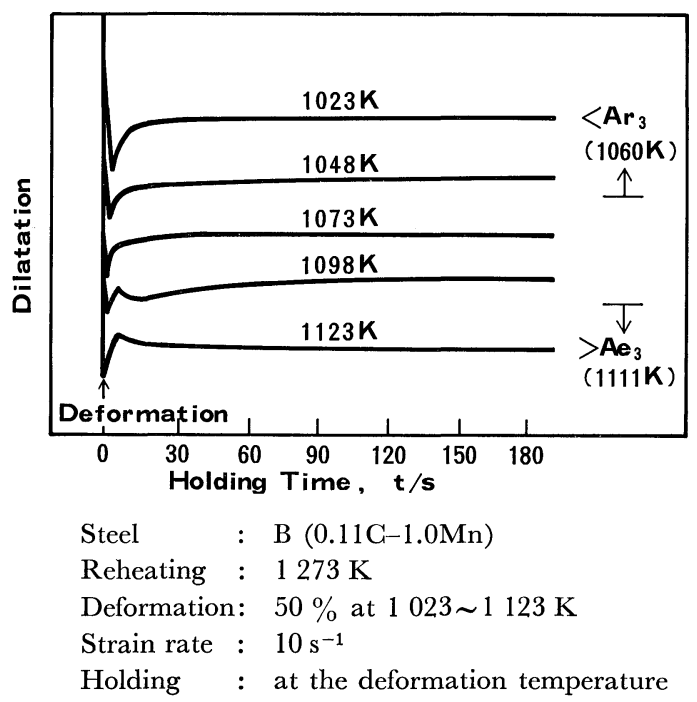

Fig. 8. Dilatational change during isothermal holding after deformation

Both grain size and fraction of ferrite transformed during deformation depend on the temperature, strain and compositions of steel. The lower deformation temperature leads to finer grains. However, when the temperature is lower than $A r_{3}$ and the reduction is not sufficient, proeutectoid ferrite which transforms before deformation produce a deformed structure which shows unfavorable ductility.

The effect of strain varies with the chemical composition of steels. When the carbon content is $0.1 \%$, grain size decreases monotonously with strain and $f_{\alpha}$ is $80 \%$ when the strain reaches 2.0. While when the carbon content is $0.15 \%$, grain size is rather constant when the strain exceeds 1.0 but $f_{\alpha}$ is less than a half of that of steel with a lower $\mathrm{G}$ content.

Figure 9 shows grain size and fraction of ferrite as a function of $A r_{3}{ }^{11)}$ As $A r_{3}$ decreases, grain size decreases but $f_{\alpha}$ also decreases. If a sufficient amount of ultrafine ferrite is desired, the compositions should

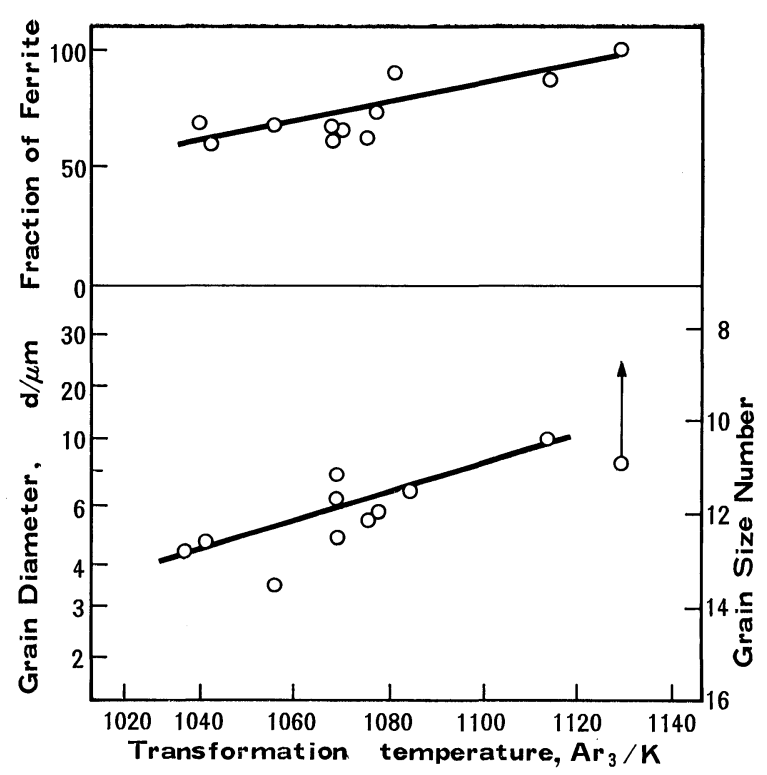

Composition : $\quad 0.05 \sim 0.15 \mathrm{C}-0 \sim 0.5 \mathrm{Si}-0.5 \sim 1.5 \mathrm{Mn}$ Reheating : $1237 \mathrm{~K}\left(\mathcal{N}_{\gamma_{0}} \fallingdotseq 1\right)$

Pass schedule: Simulation of 5-pass hot strip rolling (Finishing speed $8.3 \mathrm{~m} \cdot \mathrm{s}^{-1}$ )

Cooling : Water quenched $2 \mathrm{~s}$ after rolling

Fig. 9. Effect of transformation temperature, $A r_{3}$, on the fraction and grain size of ferrite in the simulated continuous rolling.

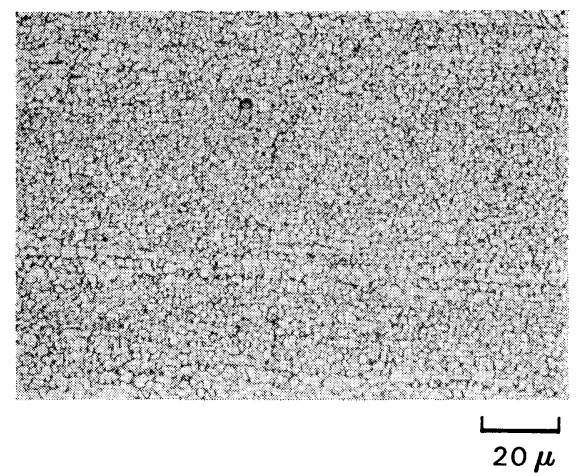

Fig. 10. Microstructure of specimen heavily deformed to a strain of 2.8 .

be adjusted so that $A r_{3}$ is a little lower than $1080 \mathrm{~K}$. The addition of elements which retard transformation is unfavorable.

Figure 10 shows the structure of steel A which was deformed at $1073 \mathrm{~K}$ with an extremely heavy reduction $(\varepsilon=2.8)$ in single stage test. The ferrite grains are not elongated but equiaxial. As the deformed specimen was water quenched with a quite small delay $(0.056 \mathrm{~s})$ after the deformation and with a sufficiently rapid cooling rate of $400 \mathrm{~K} / \mathrm{s}$ to prevent the diffusional growth, the equiaxed grains were supposed to be present prior to the quenching. As ferrite can form even when the deformation strain is not very large (see the dotted lines in Fig. 4), some amounts of ferrite grains must have been transformed during the heavy deformation. The ferrite grains transformed at the early stage of the deformation 
would be elongated in the subsequent stage of the deformation. Nevertheless the ferrite grains appear equiaxial without elongation. This implies that the ferrite has dynamically recrystallized during deformation. Fineness of grains is a necessary condition for dynamic recrystallization of ferrite. The size of ferrite grains which formed by deformation induced transformation seems to be sufficiently small. Although the ferrite usually does not recrystallize dynamically, Watanabe reported the occurrence of dynamic recrystallization of ferrite in the case of intercritical rolling. ${ }^{12)}$ The concentration of strain to ferrite, which is softer than austenite, seems to be also necessary.

As stated so far, it is clear that ferrite can form at relatively high temperatures during hot deformation. Only if the interpass time of successive deformations is sufficiently short, the ferrite grains become fine by the following two reasons. One is the effect of accumulative strain, in other words, accumulation of dislocations. Accumulative strain acts like single stage large deformation to increase transformation sites. The other is the occurrence of recrystallization of existing ferrite grains. As fine grains are easier to recrystallize than coarser grains, it is important to give the subsequent deformation before the existing ferrite grains grow. According to the results in Fig. 3 , whenever the deformations are given within $2 \mathrm{~s}$, the resultant grain size is as fine as $2 \mu \mathrm{m}$ (No. 14). Thus any reverse rolling with a longer interpass time than $2 \mathrm{~s}$ such as plate rolling is not suitable for obtaining ultrafine grains. An actual interpass time in the successive rolling lies between $0.2 \sim 8 \mathrm{~s}$, so that the last 3 or 4 passes of the hot successive rolling may replace the single stage large deformation. This means that an actual hot successive rolling in plant can produce a steel sheet of ultrafine ferrite grains by increasing reduction in the last 3 or 4 passes.

According to the above results, a hot successive strip rolling was tried in a production mill to roll a $3.5 \mathrm{~mm}$ thick strip of $0.13 \mathrm{C}-0.32 \mathrm{Si}-1.07 \mathrm{Mn}$ steel. The reduction of the final pass was $27 \%$, the final rolling speed was $700 \mathrm{mpm}$ and the finish rolling temperature was $1043 \mathrm{~K}$. The results were promising. The mean ferrite grain size was very fine; No. 13.5 as shown in Fig. 11, in good agreement with the simulation test.

Figure 12 shows an example of transmission electron micrographs of the hot strip. The ferrite grains exhibit a wide variation in the grain diameter and the dislocation density. The variety of the contrast of each grain indicates a random distribution in the orientation of grains, which was verified by the analysis of diffraction patterns. The detailed description will be shown elsewhere.

\section{Conclusions}

The effect of the successive deformation on the refinement of ferrite grains in low carbon steels during multi-pass deformations at temperature just above $\mathrm{Ar}_{3}$ temperature was studied by using a hot deformation simulator and a rolling mill. The

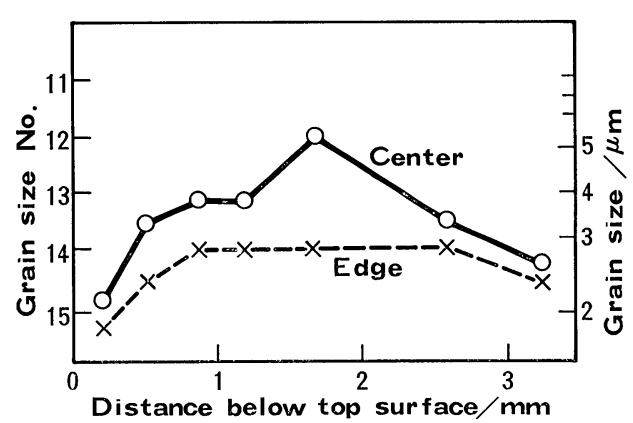

Fig. 11. Grain size distribution through thickness of actually rolled strip.

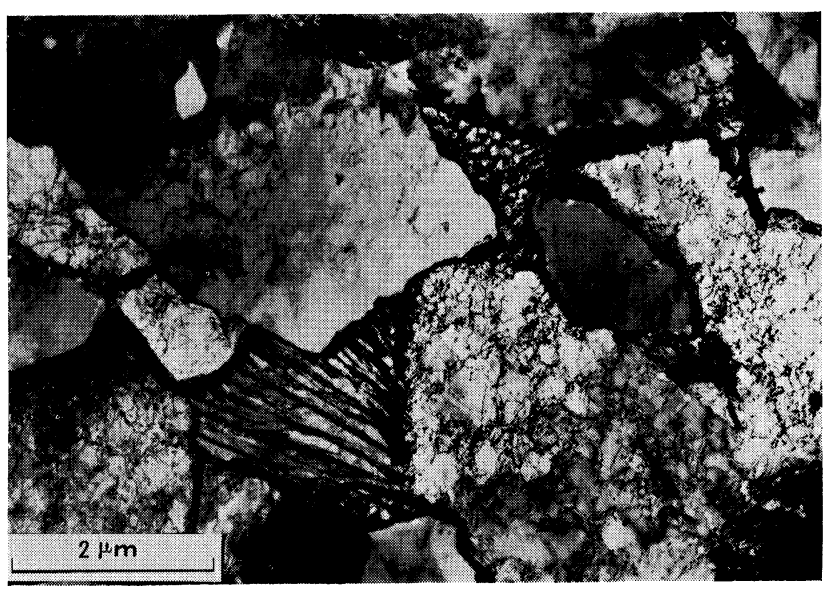

Fig. 12. Thin foil electron micrograph of the hot strip of $0.13 \mathrm{C}-0.32 \mathrm{Si}-1.07 \mathrm{Mn}$ steel.

results showed that the fraction of fine ferrite increases and the grain size can be decreased or remain small after the 2 nd deformation of a 2-pass test.

The 6-stage experiment simulating the hot strip rolling in plant suggested a possibility of producing ultrafine-grained steels in commercial practice. A trial of rolling brought promising results.

\section{Acknowledgements}

The authors express their hearty thanks to Dr. T. Senuma, Messrs. K. Terazawa, A. Takahashi and Y. Matsuo for their discussions and their collaboration in the dilatometry measurement and the electron microscopy. Their thanks are also due to $\mathrm{Mr}$. T. Asamura, Dr. T. Kikuma and many other people of Yawata Works, Nippon Steel Corp., who conducted the trial rolling in the hot strip mill.

\section{REFERENCES}

1) C. M. Sellars: Hot Working and Forming Process, Met. Soc., Sheffield, (1980), 3.

2) W. Roberts, A. Sandberg, T. Siwecki and T. Werlefors: HSLA Steels Technology \& Applications, ASM, Ohio, (1983), 67.

3) H. Yada, Y. Matsumura, I. Matsuo, T. Senuma, T. Terazawa and K. Nakajima: Collected Abstracts of the 1983 Autumn Meeting of Japan Inst. Metals., JIM, Sendai, (1983), 190 and the 1984 Autumn Meeting of Japan Inst. Metals, JIM, Sendai, (1984), 156.

4) H. Yada, Y. Matsumura, K. Nakajima and N. Matsuzu: 
Tetsu-to-Hagané, 69 (1983), S1459.

5) Y. Matsumura and H. Yada: The Metallurgical Soc. Tech. Paper No. A86-28, (1986).

6) Y. Matsumura and H. Yada: Tetsu-to-Hagané, 70 (1984), S654.

7) H. Yada, N. Matsuzu, K. Nakajima, K. Watanabe and H. Tokita: Trans. ISIJ, 23 (1983), 34.

8) W. Lehnert and K.-A. Behr: Neue Hütte, 15 (1970), 355.
9) M. Fukuda, T. Hashimoto and K. Kunishige: Tetsu-toHagané, 58 (1972), 1832.

10) H. Yada, Y. Matsumura and T. Senuma: Preprint of ICOMAT-86, JIM, Sendai, (1986), 21.

11) H. Yada, Y. Matsumura, T. Senuma, T. Terazawa and A. Takahashi: Collected Abstracts of the 1986 Autumn Meeting of Japan Inst. Metals, JIM, Sendai, (1986), 128.

12) K. Watanabe: Tetsu-to-Hagané, 71 (1985), 1926. 